\title{
Caudate Volume in Offspring at Ultra High Risk for Alcohol Dependence: COMT Val158Met, DRD2, Externalizing Disorders, and Working Memory
}

\author{
Shirley Y. Hill, ${ }^{1,2 \#}$, Sarah Lichenstein ${ }^{1,2}$, Shuhui Wang ${ }^{1}$, Howard Carter ${ }^{1}$, Michael McDermott ${ }^{1}$ \\ ${ }^{1}$ Department of Psychiatry, University of Pittsburgh School of Medicine, Pittsburgh, USA \\ ${ }^{2}$ Department of Psychology, University of Pittsburgh, Pittsburgh, USA \\ Email: "\#yh50@imap.pitt.edu
}

Received July 26, 2013; revised August 26, 2013; accepted September 3, 2013

Copyright (C) 2013 Shirley Y. Hill et al. This is an open access article distributed under the Creative Commons Attribution License, which permits unrestricted use, distribution, and reproduction in any medium, provided the original work is properly cited.

\begin{abstract}
Background: There is emerging evidence that the increased susceptibility to developing alcohol and substance use disorders in those with a family history of Alcohol Dependence (AD) may be related to structural differences in brain circuits that influence the salience of rewards or modify the efficiency of information processing. Externalizing disorders of childhood including Attention Deficit Hyperactivity Disorder, Conduct and Oppositional Disorders are a prominent feature of those with a positive family history. The caudate nuclei have been implicated in both the salience of rewards and in the pathophysiology of alcohol dependence and these often antecedent childhood disorders. Methods: Adolescent/young adult high and low-risk for $\mathrm{AD}$ offspring $(\mathrm{N}=130)$ were studied using magnetic resonance imaging. Volumes of the caudate nucleus were obtained using manual tracing with BRAINS2 software and neuropsychological functioning determined. Childhood disorders were assessed as part of a long-term longitudinal follow-up that includes young adult assessment. Dopaminergic variation was assessed using genotypic variation in the catechol-O-methyltransferase (COMT) and DRD2 genes. Results: High-risk subjects showed poorer Working Memory functioning. Caudate volume did not differ between high and low-risk subjects, but those with externalizing disorders of childhood showed reduced caudate volume. Variation in COMT and DRD2 genes was associated with Working Memory performance and caudate volume. Conclusions: Caudate volume is reduced in association with externalizing disorders of childhood/adolescence. Working Memory deficits appear in familial high-risk offspring and those with externalizing disorders of childhood. The dopaminergic system appears to be involved in both working memory performance and externalizing disorders of childhood.
\end{abstract}

Keywords: Caudate; High-Risk; COMT; DRD2; MRI; Working Memory

\section{Introduction}

The striatum, and particularly the caudate nucleus, interacting with frontal circuitry, plays an important role in the formation of reward based stimulus-response associations and in classification learning [1-3]. Drugs of abuse appear to bypass the adaptive mechanism built in for other types of rewards such as food and water, rendering drug conditioned stimuli much more difficult to eradicate.

Volumetric studies of the caudate have been undertaken in individuals with a variety of psychiatric disorders to uncover possible structural/functional relation-

\footnotetext{
*All authors report no biomedical financial interests or potential conflicts of interest.

${ }^{\#}$ Corresponding author.
}

ships between fronto-striatal circuitry and development of the disorders. Among the most prominent of these are studies of individuals with externalizing disorders of childhood and adolescence (Attention Deficit Hyperactivity Disorder [ADHD], Conduct and Oppositional disorders). Neuroimaging studies of children with ADHD [4-6] and Oppositional Defiant Disorder (ODD)/Conduct Disorder $[7,8]$ have documented structural alterations of the caudate nucleus.

Externalizing disorders occur more frequently in families with alcohol dependence $[9,10]$ and appear to be antecedents of later development of substance use disorders. Conduct Disorder (CD), a common externalizing disorder of childhood, frequently appears as a prodromal sign for later development of substance use disorders and 
has been shown to have shared genetic risk factors with alcohol dependence [11]. The caudate nucleus has one of the highest levels of dopamine DRD2 receptors in the human brain [12]. Dopamine plays a key role in rewardbased learning [13,14], and in addiction. Additionally, DRD2 receptor density and binding differs in addicted individuals and their relatives [15-20]. Accordingly, caudate volume may represent a neurobiological underpinning for a shared endophenotype for both substance use disorder (SUD) and externalizing disorders.

Catechol-O-Methyl-Transferase (COMT), a methylation enzyme that metabolizes dopamine released into the synaptic cleft [21] is one of the primary mechanisms regulating dopaminergic activity in the frontal cortex [2224]. Genetic variation in the COMT gene has been reported to differ in those with alcohol, opiate and cocaine dependence relative to controls [25-27] as has DRD2 variation [28-30].

Executive functioning has been defined as the capacity to engage in purposeful goal-directed activities [31] and usually includes measures of attention, problem-solving, working memory and inhibitory control. Deficits in executive functioning in individuals with drug and alcohol dependence [32] and those at higher risk for developing these disorders due to their family history [33-35] have frequently been reported (See 36 for review). Dopaminergic activity plays a major role in the regulation of executive functioning in the prefrontal cortex [24]. Presence of the COMT Met allele is associated with higher levels of prefrontal dopamine and appears to have a positive effect on executive functioning [37]. Also, COMT and DRD2 conjointly affect working memory performance [38-40].

Morphometric differences associated with dopaminergic genetic variation have been reported. COMT Val allele carriers show increases in age-related temporal gray matter with Met carriers showing decreased gray and white matter volume in parietal, frontal and parahippocampal regions [41], and Val homozygotes showing reduced total volume of the temporal lobe and hippocampus [42]. An association between DRD2/ANKK1 variation and caudate volume has been reported [43] with Taq1a A2 homozygotes having decreased left caudate volume.

The present study was designed to investigate whether offspring from multiplex alcohol dependent families who are at ultra high risk for addictive behaviors might exhibit volumetric differences in the caudate nucleus compared to low-risk offspring from families with no history of AD. Because externalizing disorders of childhood and adolescence are frequently seen in high-risk offspring, it was of interest to determine if the presence or absence of externalizing disorders might be related to caudate volume.

Additional goals included examination of familial risk group membership, presence or absence of an external- izing disorder, and their relationship to neuropsychological performance. Based on previous reports of impaired executive functioning in offspring of alcohol dependent individuals [36] and evidence that the caudate is involved in attention and executive functioning [44], we hypothesized that offspring with multiple cases of alcohol dependent family members would exhibit neuropsychological impairment in functions involving attention and executive functions. Also, our plan included investigation of the neurobiological underpinnings of these neuropsychological deficits by relating them to a possible association with caudate volume and DRD2 and COMT genetic variation.

We reasoned that studying offspring at very high risk for developing alcohol dependence due to their multiplex familial loading might provide insight into the functional deficits seen in high-risk offspring and the possible neural substrate variation associated with this risk.

\section{Methods}

\subsection{Participants}

The sample included 71 high-risk subjects from multiplex families ( 38 male and 33 female) and 59 low-risk controls (27 male and 32 female) (Table 1). Of these, 68 were scanned between the ages of 8 to 18 while 62 offspring had reached their $19^{\text {th }}$ birthday by the time they were scanned as young adults.

The high and low-risk (control) children/adolescents are participants in an ongoing family study in which offspring of parents with either high genetic loading for alcohol dependence (high-risk) or those whose parents had minimal loading (low-risk) are contrasted. The high-risk families had been identified through a proband pair of alcohol dependent brothers as previously described [9].

All participants signed informed consent documents after having the study explained to them. Participants were screened to insure absence of ferromagnetic metal in or on their body. All female subjects were screened for pregnancy using Icon ${ }^{\circledR} 25 \mathrm{hCG}$ pregnancy kits.

\subsection{Diagnoses}

Each child/adolescent and his/her parent were separately administered the Schedule for Affective Disorders and Schizophrenia (K-SADS) [45] by trained interviewers and a best estimate diagnosis determined as previously described $[9,46]$. The Composite International Diagnostic Interview (CIDI) [47] was administered to those age 19 or older to determine the presence or absence of a DSMIV Axis I diagnosis. The CIDI-SAM (Substance Abuse Module) [48] was given to obtain quantity, frequency, and pattern of drug usage. Inter-rater reliability for the diagnostic instruments exceeded $90 \%$. 
Table 1. Demographic Characteristics of High and Low-Risk Adolescents and Young Adults. Mean and standard deviation (SD) for all high and low-risk offspring are presented. There were 38 high-risk and 27 low-risk males and 33 high-risk and 32 low-risk females.

\begin{tabular}{|c|c|c|c|c|c|c|c|c|}
\hline & \multicolumn{2}{|c|}{ High-Risk (N = 71) } & \multicolumn{2}{|c|}{ Low-Risk (N = 59) } & \multirow[b]{2}{*}{$\mathbf{F}$} & & \multirow[b]{2}{*}{ df } & \multirow[b]{2}{*}{$\mathbf{p}$} \\
\hline & Mean & SD & Mean & SD & & & & \\
\hline Age & 18.10 & 4.20 & 17.60 & 5.80 & 0.37 & 1 & 129 & NS \\
\hline SES $^{\mathrm{a}}$ & 39.43 & 13.67 & 44.50 & 14.82 & $4.04^{\mathrm{c}}$ & 1 & 72.7 & 0.048 \\
\hline $\mathbf{I Q}^{\mathrm{b}}$ & 109.27 & 14.69 & 113.70 & 17.15 & 2.48 & 1 & 127 & NS \\
\hline BMI Male & 24.36 & 5.12 & 22.66 & 3.73 & 2.16 & 1 & 64 & NS \\
\hline BMI Female & 23.27 & 5.02 & 25.68 & 6.29 & 2.94 & 1 & 64 & NS \\
\hline $\begin{array}{l}\text { Number Right Handed } \\
\text { (\%) Right handed }\end{array}$ & $\begin{array}{c}68 \\
(95.8)\end{array}$ & & $\begin{array}{c}55 \\
(93.2)\end{array}$ & & $0.41^{\mathrm{c}}$ & 1 & & NS \\
\hline Alcohol or Drug Abuse/Dependence ${ }^{\mathrm{d}}$ & 19 & & 4 & & $8.83^{c}$ & 1 & & 0.003 \\
\hline
\end{tabular}

${ }^{a}$ Hollingshead Four Factor Index [68] was based on parental SES at initial entry into the longitudinal study. The Hollingshead group classification places individuals with numerical values between 30 - 39 in Group III (skilled craftsmen, clerical and sales workers). Those with values between 40 - 54 fall in Group IV (medium size business owners, and minor professional, and technical occupations). Accordingly, the mean values for the low-risk group would be at the lower end of Group IV and the high-risk group would be at the high end of Group III; ${ }^{\mathbf{b}}$ Peabody Picture Vocabulary Test [69]; ${ }^{\mathbf{c}} \mathrm{Chi}$ square value; ${ }^{\mathbf{d}}$ Number of cases meeting criteria for alcohol or drug abuse or dependence before their scan. Diagnoses were made using the age appropriate diagnostic instrument, KSADS for those under age 19 and CIDI for those 19 or greater. Three cases were diagnosed before the age of 19 and had a mean exposure period of $0.33 \pm 0.57$ years prior to the MRI scan. The remaining 19 cases were diagnosed after age 19 and had a mean exposure of $2.47 \pm 2.32$ years before the scan.

Mothers of both high and low-risk offspring were administered a structured interview at the time of the child's first longitudinal assessment designed to assess quantity and frequency of use of alcohol, drugs and cigarettes during pregnancy.

\subsection{Image Acquisition}

All subjects were scanned on a GE 1.5 Tesla scanner located in the Department of Radiology MR Research Center. T1 weighted axial images with slice thickness of $1.5 \mathrm{~mm}$ were obtained using a 3 dimensional spoiled gradient recalled echo in the steady state (3D SPGR) (TE $=5, \mathrm{TR}=24$, flip angle $=45$ degrees, acquisition matrix $=192 \times 256, \mathrm{NEX}=1, \mathrm{FOV}=24 \mathrm{~cm})$. Slices were resliced in the coronal plane through the anterior commissures to provide a more reproducible guide for image orientation. Additionally, axial proton density and T2 weighted images were obtained covering the whole brain at a slice thickness of $5 \mathrm{~mm}$, slice gap $=0 \mathrm{~mm}$ ([double echo spin echo, $\mathrm{TE}=17 \mathrm{~ms}$ and $102 \mathrm{~ms}$; TR $=3000 \mathrm{~ms}$ ], acquisition matrix $=256 \times 192, \mathrm{NEX}=1, \mathrm{FOV}=24 \mathrm{~cm}$ ). Obtaining the dual echo study enabled us to adequately address segmentation. A neuroradiologist reviewed scans with suspected structural abnormalities.

\subsection{Region of Interest Analysis}

Caudate and intracranial volumes were measured using BRAINS2 [49], a software that provides valid and reliable volume measurements of specific structures by using a semiautomated segmentation approach. Manual tracing is preferable to automated methods for the study of smaller subcortical structures [50] and in subjects with developing brains as suggested by Carrey et al [4]. Two raters
(SW and $\mathrm{HC}$ ) blind to the identity and risk group membership traced the volumes of the caudate and intracranial volume (ICV). Tracing of the caudate included the head of the caudate and was bounded by frontal white matter anteriorally, the anterior commissure posteriorally, internal capsule laterally, and using a thin band of white matter medially (Figure 1). The end boundary was determined by the point where the body of caudate could no longer be distinguished from the wall of the lateral ventricle. These boundaries have previously been described by Looi et al. [51] though their method utilized tracings in the axial plane while we used the coronal plane.

\subsection{Neuropsychological Assessment}

A battery of neuropsychological tests was administered to each participant to assess neurocognitive functioning in domains consisting of intelligence, visual attention, language/verbal fluency, memory, and executive skills. Test scores for children and young adults were combined using scaled scores.

Executive Functioning-Trails and Stroop Performance. Two age appropriate versions (child and adult) of the Trail Making Test (Part A and B) [52,53] were administered. Scores were adjusted for age using norms provided by Reitan [54] for the younger participants (ages 8 - 15 years), and norms from Tombaugh [55] for the young adult sample (ages $18-24$ years). A Trails difference score thought to assess cognitive control and taskswitching abilities [56] was also calculated (TMT-B minus TMT-A). The Stroop Color Word Test (STR CW) [57] was also given.

Memory. The Wechsler Memory Scales, $3^{\text {rd }}$ Edition (WMS-III) [58] were administered to individuals over 


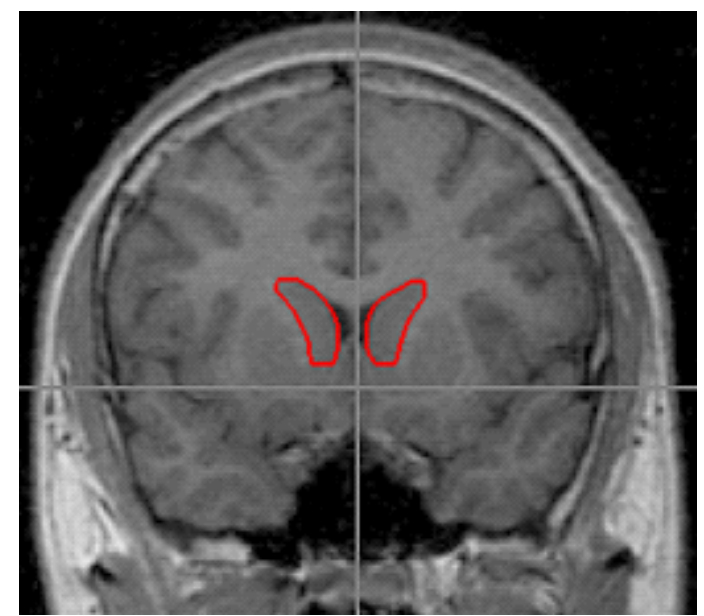

Figure 1. Outlines of the right and left caudate were traced using BRAINS2 software and following the method of Looi et al. 2008. Tracing of the caudate included the head of caudate bounded by frontal white matter anteriorally, the anterior commissure posteriorally, the internal capsule laterally, and by a thin band of white matter medially. The end boundary was determined by the point where the body of caudate could no longer be distinguished from the wall of the lateral ventricle.

the age of 17 and the Children's Memory Scale (CMS) to those under age 17. The CMS includes subtests that tap functions assessed by WMS-III so that corresponding scaled scores could be combined for analysis.

\subsection{Genotyping}

DNA was available for 103 Caucasian subjects (62 highrisk and 41 low-risk offspring) for whom structural MRI scans were obtained. Genetic variation in DRD2 and catechol-O-methyl transferase (COMT) was assessed.

DRD2 and COMT genotyping was completed using the SNPs rs6277 and rs4680 analyzed on the Biotage PSQ 96MA Pyrosequencer (Biotage AB, Uppsala, Sweden). An amplimer containing the polymorphism was generated by PCR in $96-$ well plates in a $50 \mu \mathrm{L}$ total reaction volume, containing $10 \mathrm{ng}$ of human genomic DNA; 1X GeneAmp ${ }^{\circledR}$ PCR Gold Buffer; $2.5 \mathrm{mM}$ magnesium chloride; $200 \mu \mathrm{M}$ dNTPs; 1 unit of AmpliTaq Gold ${ }^{\mathrm{TM}}$ taq polymerase; and $10 \mathrm{pmol}$ of an unmodified forward primer and a 10 pmol biotinylated reverse primer. Thermal cycling included 45 cycles at an annealing temperature of 60 degrees.

For the DRD2 genotyping (rs6277), the unmodified forward primer used was 5'-CACCACGGTCTCCACAGCA-3' and the biotinylated reverse primer 5'-GGGCATGGTCTGGATCTCAAA-3'. The Biotage workstation was used to isolate the biotinylated single strand from the double strand PCR products. The isolated product was then sequenced using the complimentary sequencing primer 5'-GGTCTCCACAGCACTC-3'. At the polymorphic site, the minor allele was detected by the presence of a $\mathrm{C}$ nucleotide whereas the major allele was detected by the presence of a $\mathrm{T}$ nucleotide.

For the COMT, the unmodified forward primer 5'AGATCGTGGACGCCGTGA-3' and the biotinylated reverse primer 5'-AACGGGTCAGGCATGCAC-3' were used. The biotinylated single strand was isolated from the double strand PCR products and sequenced using the complimentary sequencing primer 5'-ATGGTGGATTTCGCT-3'. The minor and major alleles were detected by the presence of an A or G nucleotide, respectively, corresponding to the Met and Val alleles.

\subsection{Statistical Analyses}

Linear Mixed Models (LMM) with random effects (SPSS version 20; SPSS, Chicago, Illinois) were used. Because some families contributed multiple siblings, a family identifier was incorporated into the LMM as a random effects variable. Mixed effects models were used to investigate the association between familial risk status (high and low-risk groups), gender, and caudate volume (total, left, and right), using gender as a fixed factor and controlling for scan age, adjusted yearly alcohol consumption, and intracranial volume (ICV).

The presence or absence of an externalizing disorder, narrow or broad, was determined for each subject. The narrow externalizing phenotype was defined by the presence of either Attention Deficit Hyperactivity Disorder [ADHD], Oppositional Defiant Disorder, or Conduct Disorder. The broad externalizing phenotype was defined by the presence of any of these disorders along with substance use disorder. Data were analyzed to determine if these phenotypes were associated with caudate volume, controlling for these same variables.

The relationships between neuropsychological functioning, caudate volumes, and genotypic variation were investigated using mixed models that also controlled for inclusion of multiple siblings from the same family. All models were run evaluating SES and prenatal use of substances with no change in the results.

\section{Results}

\subsection{Demographic Information}

Demographic information for the high and low-risk subjects are presented in Table 1. No significant differences were observed between groups for age, IQ, body mass index, or handedness. Mean values of socioeconomic status (SES) differed by risk group.

\subsection{Personal Psychiatric History}

Familial risk group differences for individual diagnoses may be seen in Tables 2(a) and (b). 
Table 2. (a) Psychiatric diagnoses for participants scanned during childhood (8 - 18 years old) by risk group; (b) Psychiatric diagnoses for participants scanned during young adulthood.

(a)

\begin{tabular}{lcccc}
\hline & High-Risk (N = 34) & \multicolumn{2}{c}{ Low-Risk (N = 34) } \\
\hline Alcohol or Drug Abuse & Number & $\%$ & Number & \% \\
Alcohol or Drug Dependence & 2 & 5.9 & 1 & 2.9 \\
Either Alcohol or Drug & 2 & 5.9 & 1 & 2.9 \\
Abuse or Dependence & 3 & 8.8 & 1 & 2.9 \\
Anxiety Disorders & 5 & 14.7 & 4 & 11.8 \\
Depression & 6 & 17.6 & 1 & 2.9 \\
ADHD & 8 & 23.5 & 1 & 2.9 \\
Oppositional Defiant Disorder or Conduct Disorder & 5 & 14.7 & 2 & 5.9 \\
\hline
\end{tabular}

Kiddie-Schedule for Affective Disorders (K-SADS) used for childhood assessments. Among the 68 offspring scanned during childhood and adolescence, high-risk offspring showed elevated rates of depression. $\left(x^{2}=3.98, \mathrm{p}=0.046\right)$, and ADHD $\left(\mathrm{x}^{2}=6.28, \mathrm{p}=0.012\right)$.

(b)

\begin{tabular}{lcccc}
\hline & High-Risk (N = 37) & \multicolumn{2}{c}{ Low-Risk (N = 25) } \\
\hline Alcohol or Drug Abuse & Number & $\%$ & Number & \% \\
Alcohol or Drug Dependence & 13 & 35.1 & 3 & 12.0 \\
Either Alcohol or Drug & 12 & 32.4 & 7 & 28.0 \\
Abuse or Dependence & 17 & 45.9 & 8 & 32.0 \\
Anxiety Disorders & 13 & 35.1 & 8 & 32.0 \\
Depression & 9 & 24.3 & 3 & 12.0 \\
ADHD & 4 & 12.1 & 0 & 0 \\
Oppositional Defiant Disorder or Conduct Disorder & 9 & 24.3 & 0 & 0 \\
\hline
\end{tabular}

Composite International Diagnostic Interview (CIDI) was used for young adult assessments. CIDI-Substance Abuse Module (CIDI-SAM) supplemented CIDI information. For the subjects scanned during young adulthood, significantly more alcohol or drug abuse was present $\left(\mathrm{x}^{2}=4.17, \mathrm{p}=0.041\right)$. Similarly, significantly more childhood ODD/Conduct had been present $\left(x^{2}=6.27, p=0.012\right)$. Using data across the child/adolescent and young adult follow up, significantly more high-risk offspring met criteria for a substance use disorder (alcohol abuse or dependence or drug abuse or dependence) $\left(\mathrm{x}^{2}=8.83, \mathrm{p}=0.003\right)$.

\subsection{Prenatal Use of Substances}

Mothers of both high and low-risk offspring reported low levels of drinking, drug use, and cigarettes during pregnancy. A total of $76.9 \%$ reported no drinking, and $23.1 \%$ drank less than 1 drink per day. A total of $2.7 \%$ reported using any drugs. Absence of cigarette use was reported by $76.6 \%$ of mothers.

\subsection{Risk Group Effects for Caudate Volume}

An association between familial risk status (high and lowrisk groups) and caudate volume (total, left, and right) was not found using a model that included gender, risk and their interaction as fixed factors, controlling for scan age, adjusted yearly alcohol consumption, and intracranial volume (ICV). Mean volumes may be seen in Table 3(a).

\subsection{Narrow Spectrum Externalizing Disorders}

Significant differences were observed for caudate volume between those with a narrow externalizing disorder and those without. The model included covariates for gender, scan age, adjusted yearly alcohol consumption, and intracranial volume (ICV). Those with a diagnosis of ADHD, or ODD/Conduct disorder had significantly smaller total caudate volume $(\mathrm{F}=5.39$, $\mathrm{df}=1,111.99, \mathrm{p}=0.022)$, right $(\mathrm{F}=5.19, \mathrm{df}=111.91, \mathrm{p}=0.025)$, and left $(\mathrm{F}=5.25$, $\mathrm{df}=111.88, \mathrm{p}=0.024)$ caudate volumes (Table $3(\mathbf{b})$ ).

\subsection{Broad Spectrum Externalizing Disorders}

Subjects falling within the broader spectrum of externalizing disorders (ADHD, Conduct/ODD, or SUD) also had significantly smaller total caudate volume $(\mathrm{F}=4.22, \mathrm{df}=$ $1,121.54, \mathrm{p}=0.042)$, and smaller right $(\mathrm{F}=4.10, \mathrm{df}=1$, $119.07, \mathrm{p}=0.045)$ and left $(\mathrm{F}=5.05, \mathrm{df}=1,115.09, \mathrm{p}=$ 0.027 ) caudate volumes compared with individuals without the broad spectrum externalizing disorder after accounting for gender, scan age, adjusted yearly alcohol consumption, and intracranial volume (ICV) (Table 3(c)).

\subsection{Neuropsychological Test Results}

Significant main effects of familial risk group membership were seen for the Working Memory test, but no other main effects of familial risk were found (Table 4). Interactions between gender and risk were seen for Visual Delayed $(\mathrm{F}=9.56, \mathrm{df}=1,107, \mathrm{p}=0.003)$, Auditory Immediate $(\mathrm{F}=4.25, \mathrm{df}=1,106, \mathrm{p}=0.042)$, and Auditory Delayed $(\mathrm{F}=4.11$, df $=1,106, \mathrm{p}=0.045)$ performance, 
Table 3. (a) Total, right and left caudate adjusted volumes by familial risk group; (b) Total, right and left caudate adjusted volumes by presence of narrow phenotype externalizing disorders of childhood; (c) Total, right and left caudate adjusted volumes by presence of externalizing disorders of childhood including child and young adulthood SUD.

(a)

\begin{tabular}{|c|c|c|c|c|c|c|c|c|}
\hline \multirow[b]{3}{*}{ Volume $\left(\mathrm{cm}^{3}\right)$} & \multicolumn{4}{|c|}{ Low-Risk Controls $(N=71)$} & \multicolumn{4}{|c|}{ High-Risk (N = 59) } \\
\hline & \multicolumn{2}{|c|}{ Males } & \multicolumn{2}{|c|}{ Females } & \multicolumn{2}{|c|}{ Males } & \multicolumn{2}{|c|}{ Females } \\
\hline & Mean & SE & Mean & SE & Mean & SE & Mean & SE \\
\hline Total Caudate & 9.34 & 0.25 & 9.79 & 0.24 & 9.38 & 0.21 & 9.36 & 0.19 \\
\hline Right Caudate & 4.64 & 0.13 & 4.91 & 0.12 & 4.68 & 0.11 & 4.68 & 0.10 \\
\hline Left Caudate & 4.70 & 0.12 & 4.88 & 0.12 & 4.71 & 0.11 & 4.68 & 0.10 \\
\hline
\end{tabular}

Adjusted means are based on adjustment for average yearly drinking density ( 84.9 drinks per year), scan age (17.9 years), and total ICV volumes (1391.26).

(b)

\begin{tabular}{|c|c|c|c|c|c|c|c|c|}
\hline \multirow[b]{3}{*}{ Volume $\left(\mathrm{cm}^{3}\right)$} & \multicolumn{4}{|c|}{ Presence of Narrow Phenotype Externalizing Disorder } & \multicolumn{4}{|c|}{ Absence of Narrow Phenotype Externalizing Disorder } \\
\hline & \multicolumn{2}{|c|}{ Males } & \multicolumn{2}{|c|}{ Females } & \multicolumn{2}{|c|}{ Males } & \multicolumn{2}{|c|}{ Females } \\
\hline & Mean & SE & Mean & SE & Mean & SE & Mean & SE \\
\hline Total Caudate & 8.89 & 0.32 & 8.91 & 0.42 & 9.56 & 0.18 & 9.60 & 0.18 \\
\hline Right Caudate & 4.41 & 0.17 & 4.47 & 0.22 & 4.77 & 0.09 & 4.81 & 0.09 \\
\hline Left Caudate & 4.47 & 0.16 & 4.44 & 0.21 & 4.79 & 0.09 & 4.79 & 0.09 \\
\hline
\end{tabular}

Adjusted means are based on adjustment for average yearly drinking density (65.6 drinks per year), scan age (17.5 years), and total ICV volumes (1395.17).

(c)

\begin{tabular}{|c|c|c|c|c|c|c|c|c|}
\hline \multirow[b]{3}{*}{ Volume $\left(\mathrm{cm}^{3}\right)$} & \multicolumn{4}{|c|}{ Presence of Broad Externalizing Disorder } & \multicolumn{4}{|c|}{ Absence of Broad Externalizing Disorder } \\
\hline & \multicolumn{2}{|c|}{ Males } & \multicolumn{2}{|c|}{ Females } & \multicolumn{2}{|c|}{ Males } & \multicolumn{2}{|c|}{ Females } \\
\hline & Mean & SE & Mean & SE & Mean & SE & Mean & SE \\
\hline Total Caudate & 9.17 & 0.23 & 9.17 & 0.26 & 9.62 & 0.20 & 9.63 & 0.17 \\
\hline Right Caudate & 4.56 & 0.12 & 4.60 & 0.14 & 4.79 & 0.10 & 4.82 & 0.09 \\
\hline Left Caudate & 4.61 & 0.12 & 4.57 & 0.13 & 4.83 & 0.10 & 4.81 & 0.09 \\
\hline
\end{tabular}

Adjusted means are based on adjustment for average yearly drinking density ( 84.9 drinks per year), scan age (17.9 years), and total ICV volumes (1391.3).

Table 4. Neuropsychological test results for three alternative phenotypes: High versus low-risk; presence or absence of a childhood externalizing disorder; presence or absence of childhood externalizing disorder or SUD.

\begin{tabular}{|c|c|c|c|}
\hline & $\begin{array}{c}\text { Risk Group }^{\mathrm{a}} \\
\text { (High-Risk versus Low-Risk) }\end{array}$ & $\begin{array}{l}\text { Narrow Externalizing } \\
\text { (Presence versus Absence) }\end{array}$ & $\begin{array}{c}\text { Broad Spectrum Externalizing } \\
\text { (Presence or Absence) }\end{array}$ \\
\hline Visual Immediate & $\begin{array}{l}F=3.14 \\
p=N S\end{array}$ & $\begin{array}{l}F=9.01 \\
p=0.003\end{array}$ & $\begin{array}{c}F=1.16 \\
p=N S\end{array}$ \\
\hline Visual Delayed & $\begin{array}{l}F=\mathbf{0 . 8 0} \\
p=\text { NS }\end{array}$ & $\begin{array}{c}F=6.13 \\
p=0.015\end{array}$ & $\begin{array}{l}F=1.80 \\
p=N S\end{array}$ \\
\hline Auditory Immediate & $\begin{array}{l}F=0.28 \\
p=N S\end{array}$ & $\begin{array}{l}F=2.14 \\
p=N S\end{array}$ & $\begin{array}{l}F=2.09 \\
p=N S\end{array}$ \\
\hline Auditory Delayed & $\begin{array}{l}F=0.17 \\
p=\text { NS }\end{array}$ & $\begin{array}{l}F=0.91 \\
p=N S\end{array}$ & $\begin{array}{l}F=0.46 \\
p=N S\end{array}$ \\
\hline General Memory & $\begin{array}{l}F=2.57 \\
p=\text { NS }\end{array}$ & $\begin{array}{l}F=6.29 \\
p=0.014\end{array}$ & $\begin{array}{c}F=13.90 \\
p=0.0001\end{array}$ \\
\hline Working Memory & $\begin{array}{c}F=5.52 \\
p=0.022\end{array}$ & $\begin{array}{l}F=10.60 \\
P=0.002\end{array}$ & $\begin{array}{l}F=5.20 \\
p=0.025\end{array}$ \\
\hline Trails A & $\begin{array}{l}F=2.85 \\
p=N S\end{array}$ & $\begin{array}{l}F=3.76 \\
p=N S\end{array}$ & $\begin{array}{l}F=4.24 \\
p=0.042\end{array}$ \\
\hline Trails B & $\begin{array}{l}F=2.30 \\
p=N S\end{array}$ & $\begin{array}{c}F=7.36 \\
p=0.008\end{array}$ & $\begin{array}{l}F=2.88 \\
p=N S\end{array}$ \\
\hline Trails B-A & $\begin{array}{c}F=2.14 \\
p=N S\end{array}$ & $\begin{array}{l}F=5.95 \\
p=0.017\end{array}$ & $\begin{array}{l}F=3.41 \\
p=N S\end{array}$ \\
\hline Stroop Interference & $\begin{array}{l}F=0.61 \\
p=N S\end{array}$ & $\begin{array}{l}F=0.29 \\
p=N S\end{array}$ & $\begin{array}{l}F=0.18 \\
p=N S\end{array}$ \\
\hline
\end{tabular}

${ }^{\mathrm{a}}$ Risk group was defined by the presence of multiple alcohol dependent family members (high-risk) or the absence of first-degree relatives with $\mathrm{AD}$ (low-risk). ${ }^{\mathbf{b}}$ Narrow externalizing disorder was defined by the presence of childhood ADHD, Oppositional or Conduct Disorders. ${ }^{\mathbf{c}}$ Broad externalizing disorder was defined by these childhood disorders and/or substance use disorder. 
largely due to the poorer performance of high-risk males relative to low-risk males. While Working Memory performance was the only significant main effect seen when high and low-risk subjects were compared, several main effects were seen when those with and without the narrow externalizing phenotype were contrasted (Visual Immediate, Visual Delayed, General Memory, Working Memory, Trails B and Trails B-A). Also, those with the broad definition of externalizing disorder that included substance use disorder showed deficits in General Memory, Working Memory, and in Trails A performance. Across all phenotypes Working Memory performance was poorer in those who were high-risk for alcohol dependence, those with narrowly defined externalizing disorder (ADHD, Oppositional or Conduct), and those with the more broadly defined externalizing pathology that included SUD.

\subsection{Neuropsychological Performance-Genetic Variation}

Previous studies have shown that working memory may be influenced by the interaction of DRD2 and COMT variation $[38,40,59]$. Due to non-random association between DRD2 variation and familial risk [30], DRD2 and COMT variation was tested along with familial risk in the present study.

\subsubsection{DRD2, COMT, and Working Memory}

An interaction between risk, DRD2 (rs6277) and COMT variation (rs4860) on working memory performance was seen $(\mathrm{F}=3.55, \mathrm{df}=7,84, \mathrm{p}=0.002)$ (Figure 2). Interaction effects were also seen in the male only $(\mathrm{F}=2.42, \mathrm{df}$ $=7,28.6, \mathrm{p}=0.045)$, and female only $(\mathrm{F}=2.12, \mathrm{df}=7$, $28.4, p=0.074)$ samples, though marginal in females. A main effect of DRD2 genotype was also seen $(\mathrm{F}=5.52$, $\mathrm{df}=1,85, \mathrm{p}=0.02)$. Overall, those homozygous for the $\mathrm{T}$ allele (TT genotype) performed more poorly than those with any $\mathrm{C}$ minor allele (CT or $\mathrm{CC}$ ).

\subsubsection{DRD2, COMT, and Caudate Volume}

The effects of DRD2 and COMT variation on total caudate volume were assessed using a statistical model that included gender and risk as covariates. Gender was highly significant $F=9.09$, df $1,77.9, p=0.003$, but the main effect of each gene or the interaction of the two genes was not. Analyses designed to evaluate the effect of each gene, gender and their interaction revealed only an effect of gender. Due to the substantial contribution of gender, analyses were done within each gender. No differences were found for COMT. For DRD2, differences were not observed for males (DRD2 minor allele mean $\pm \mathrm{SE}=$ $9.68 \mathrm{cc} \pm 0.24$ versus $9.83 \mathrm{cc} \pm 0.33$ ), but for females volume was larger for those with the minor allele $(9.38$
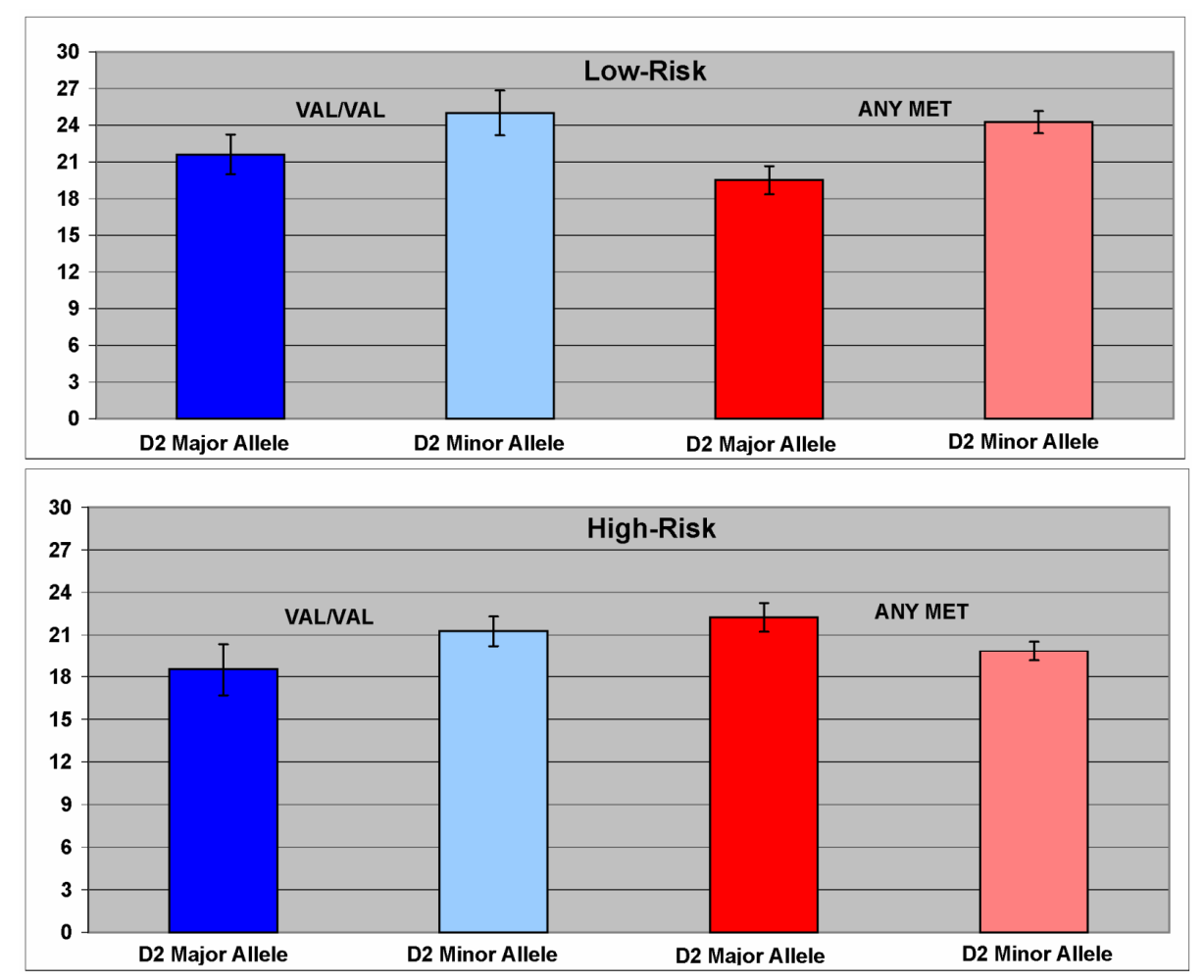

Figure 2. The interaction between DRD2 (rs6277) and COMT (rs4860) variation was associated with working memory performance. Presence of any C minor allele of the DRD2 SNP rs6277 was associated with better working memory performance than that observed in TT homozygotes. 
$\mathrm{cc} \pm 0.21)$ than it was for those without a minor allele $(8.78 \mathrm{cc} \pm 0.25)$ resulting in a marginally significant effect $(F=3.84, d f=1,40.6, p=0.057)$.

\subsubsection{DRD2, COMT, and Externalizing Disorders of Childhood}

Using a binary logistic regression, DRD2, COMT, and their interaction were tested as covariates as predictors of broad externalizing disorder with gender and familial risk. The narrow phenotype was not tested due to insufficient cases. Broad spectrum externalizing disorder was marginally associated with DRD2 variation $(\mathrm{F}=3.24, \mathrm{df}=1$, $98, \mathrm{p}=0.075)$. Familial risk was a significant covariate $(\mathrm{F}=6.15, \mathrm{df}=1,98, \mathrm{p}=0.015)$.

\section{Discussion}

Because alcohol and/or drug exposure might be expected to have neuropathological effects that could result in reduced volume of the caudate [60], externalizing disorder was examined in those without SUD (narrow spectrum externalizing disorder) and in those with SUD (broad spectrum externalizing disorders). Reduced caudate volume was associated with both the narrow and the broad spectrum externalizing disorder phenotypes suggesting that caudate volume may be an etiological predictor of substance use disorder vulnerability and not simply the result of alcohol/drug exposure.

Although familial risk group differences in caudate volume were not seen, externalizing disorder sprectra (broad or narrow) were associated with caudate volume. This is in accord with other studies of externalizing disorders, particularly those with ADHD [6,61-63].

The present study found relatively few neuropsychological differences between those with multiple cases of alcohol dependence in their family and those without such a history. Among the differences observed was poorer Working Memory (WM) performance. Poorer WM performance was also observed for those with externalizing disorders (narrow or broad phenotype). Based on previous reports of a relationship between COMT, DRD2, and/or their interaction with Working Memory performance [38-40,59], WM performance and genetic variation were assessed. The present results are in accord with Jacobsen et al. [59] in finding poorer performance in the C957T T carriers, and support findings of others [38-40] in finding performance changes in association with DRD2 and COMT genetic variation.

Although an interaction effect between DRD2 and COMT on caudate volume was not seen, variation in the DRD2 gene interacted with gender to influence caudate volume, with females who were minor allele carriers showing larger caudate volume than those who were homozygous for the major allele. This finding is in accord with a previous report showing an association between DRD2 and caudate volume [43].

\section{Limitations of the Study}

Homozygous groups (Met/Met versus Val/Val) have been contrasted to observe differences in cognitive performance [64] where maximal differences in COMT efficiency can be expected [22]. Because of limited sample size, the present study analyzed minor allele heterozygotes and minor allele homozygotes together precluding conclusions regarding Met/Met versus Val/Val comparisons.

Use of a single SNP to characterize genetic variation of the DRD2 and COMT genes is not ideal. However, the C957T locus (rs6277) within the DRD2 gene alters extrastriatal binding potential [65], and is significantly associated with alcohol dependence $[30,66]$. Similarly, allelic variation in the rs4680 SNP appears to reliably measure variation in COMT activity and quantity of protein produced [22].

The study included both children and young adults requiring use of different test procedures. Although a limitation, this was offset by use of scaled scores that allowed combining of data across age ranges. Another potential limitation was that the mean SES differed by risk group. However, analyses performed using SES as a covariate on caudate volume and neuropsychological functioning showed no alteration of results. Another potential limitation was that some offspring experienced in utero exposure to alcohol, cigarettes or other drugs. However, an analysis using prenatal exposure as a covariate did not alter the results obtained. Also, mothers' self report measures indicated minimal drinking that was comparable to that seen in the general population. Survey data from obstetric clinics in Southeastern Michigan has shown that $81.9 \%$ of the mothers drink less than 1 drink per week [67]. In our sample, $76.3 \%$ of the mothers reported no drinking during pregnancy.

While this report did not include analyses of other brain structures, the plan was hypothesis-driven and based on extensive documentation of striatal involvement in addiction. Had the study used an automated method for determination of brain volumes, multiple other structures could have been assessed for comparison. However, manual tracings though labor-intensive continues to be the gold standard of volumetric analysis [50].

\section{Conclusions}

Comparison of offspring from high and low familial risk for alcohol dependence families did not reveal differences in caudate volume. However, externalizing disorders of childhood (narrow spectrum externalizing disorder) was associated with smaller caudate volume. Also, DRD2 
variation and gender were associated with caudate volume. When genetic variation was assessed with respect to presence of externalizing disorders, an effect of DRD2 variation was seen. Differences in working memory performance were seen when high- and low-risk offspring were contrasted. Poorer WM performance was also observed for those with externalizing disorders (narrow or broad phenotype). Importantly, working memory performance was also significantly related to the interaction of DRD2 and COMT variation.

In summary, the present study finds reduced caudate volume significantly related to the presence of an externalizing disorder of childhood which appears to predate the onset of alcohol dependence rather than reflecting alcohol exposure because those with the narrow externalizing phenotype without SUD showed reduced volume. Although familial risk group differences in caudate volume were not observed, familial risk for alcohol dependence increases the likelihood of experiencing externalizing disorders of childhood, which may be mediated by reduced caudate volume. Our findings are in accord with evidence that striatal structures including the caudate are components of functional networks involved in attention and goal directed action.

\section{Acknowledgements}

This research was supported by NIAAA Grants AA018289, AA05909, AA 08082, and AA015168 to SYH.

We wish to thank our research associates Nicholas Zezza and Scott Stiffler for performing the genotyping used in this manuscript and our clinical research associates, Bryan Kostelnik, MSW, Carole Turocy Mazotta, MSW, for clinical evaluations, Brian Holmes, and Jeannette Locke Wellman for database management. We also wish to acknowledge Konsale Prasad, M.D., Ph.D. and Matcheri Keshavan, M.D. for providing initial training opportunities for manual tracing. We greatly appreciate the support and cooperation of members of the families who have continued to participate in the longitudinal followup.

\section{REFERENCES}

[1] P. A. Woicik, C. Urban, N. Alla-Klein, A. Henry, T. Maloney, et al., "A Pattern of Perseveration in Cocaine Addiction May Reveal Neurocognitive Processes Implicit in the Wisconsin Card Sorting Test," Neuropsychologia, Vol. 49, No. 7, 2011, pp. 1660-1669.

http://dx.doi.org/10.1016/j.neuropsychologia.2011.02.037

[2] M. Haruno, T. Kuorda, K. Doya, K. Toyama, M. Kimura, et al., "A Neural Correlate of Reward-Based Behavioral Learning in Caudate Nucleus: A Functional Magnetic Resonance Imaging Study of Stochastic Decision Task," The Journal of Neuroscience, Vol. 24, No. 7, 2004, pp. 1660-1665.
http://dx.doi.org/10.1523/JNEUROSCI.3417-03.2004

[3] C. A. Seger, and C. M. Cincotta, "The Roles of the Caudate Nucleus in Human Classification Learning," The Journal of Neuroscience, Vol. 25, No. 11, 2005, pp. 29412951. http://dx.doi.org/10.1523/JNEUROSCI.3401-04.2005

[4] N. Carrey, D. Bernier, M. Emms, E. Gunde, S. Sparkes, et al., "Smaller Volumes of Caudate Nuclei in Prepubertal Children with ADHD: Impact of Age," Journal of Psychiatric Research, Vol. 46, No. 8, 2012, pp. 1066-1072. http://dx.doi.org/10.1016/j.jpsychires.2012.04.025

[5] E. M. Valera, S. V. Faraone, K. E. Murray, L. J. Seidman, "Meta-Analysis of Structural Imaging Findings in Attention-Deficit/Hyperactivity Disorder," Biological Psychiatry, Vol. 61, No.12, 2007, pp. 1361-1369. http://dx.doi.org/10.1016/j.biopsych.2006.06.011

[6] A. Qiu, D. Crocetti, M. Adler, E. M. Mahone, M. B. Denckla, et al., "Basal Ganglia Volume and Shape in Children with Attention Deficit Hyperactivity Disorder," The American Journal of Psychiatry, Vol. 166, No. 1, 2009, pp. 74-82.

http://dx.doi.org/10.1176/appi.ajp.2008.08030426

[7] E. C. Finger, A. A. Marsh, D. G. Mitchell, M. E. Reid, C. Sims, et al., "Abnormal Ventromedial Prefrontal Cortex Function in Children with Psychopathic Traits During Reversal Learning," Archives of General Psychiatry, Vol. 65, No. 5, 2008, pp. 586-594. http://dx.doi.org/10.1001/archpsyc.65.5.586

[8] K. Rubia, R. Halari, A. B. Smith, M. Mohammed, S. Scott, et al., "Dissociated Functional Brain Abnormalities of Inhibition in Boys with Pure Conduct Disorder and Boys with Pure Attention Deficit Hyperactivity Disorder," The American Journal of Psychiatry, Vol. 165, No. 7, 2008, pp. 889-897.

http://dx.doi.org/10.1176/appi.ajp.2008.07071084

[9] S. Y. Hill, S. Shen, L. Lowers, J. Locke-Wellman, A. G. Matthews and M. McDermott, "Psychopathology in Offspring from Multiplex Alcohol Dependence Families With and Without Parental Alcohol Dependence: A Prospective Study During Childhood and Adolescence," Psychiatry Research, Vol. 160, No. 2, 2008, pp. 155-166. http://dx.doi.org/10.1016/i.psychres.2008.04.017

[10] S. Y. Hill, K. D. Tessner and M. D. McDermott, "Psychopathology in Offspring from Families of Alcohol Dependent Female Probands: A Prospective Study," Journal of Psychiatric Research, Vol. 45, No. 3, 2011, pp. 285294. http://dx.doi.org/10.1016/j.jpsychires.2010.08.005

[11] W. S. Slutske, A. C. Heath, S. H. Dinwiddie, P. A. F. Madden, K. K. Bucholz, et al., "Common Genetic Risk Factors for Conduct Disorder and Alcohol Dependence," Journal of Abnormal Psychology, Vol. 107, No. 3, 1998, pp. 363-374.

http://dx.doi.org/10.1037/0021-843X.107.3.363

[12] R. M. Kessler, W. O. Whetsell, S. Ansari, J. R. Votaw, T. de Paulis, et al., "Identification of Extrastriatal Dopamine D2 Receptors in Post Mortem Human Brain with $\left[{ }^{125}\right]$ Epidepride," Brain Research, Vol. 609, No. 1-2, 1993, pp. 237-243.

http://dx.doi.org/10.1016/0006-8993(93)90878-Q

[13] J.-C. Dreher, P. Kohn, B. Kolachana, D. R. Weinberger 
and K. F. Berman, "Variation in Dopamine Genes Influence Responsivity of the Human Reward System," Proceedings of the National Academy of Sciences of the United States of America, Vol. 106, No. 2, 2009. pp. 617622. http://dx.doi.org/10.1073/pnas.0805517106

[14] G. D. Chiara and V. Bassareo, "Reward Systems and Addiction: What Dopamine Does and Doesn't Do," Current Opinion in Pharmacology, Vol. 7, No. 1, 2007, pp. 69-76. http://dx.doi.org/10.1016/j.coph.2006.11.003

[15] N. D. Volkow, J. S. Fowler, G. J. Wang, R. Hitzemann, J. Logan, et al., "Decreased Dopamine D2 Receptor Availability is Associated with Reduced Frontal Metabolism in Cocaine Abusers," Synapse, Vol. 14 No. 2, 1993, pp. 169177. http://dx.doi.org/10.1002/syn.890140210

[16] N. D. Volkow, G. J. Wang, J. S. Fowler, J. Logan, S. J. Gatley, et al., "Decreased Striatal Dopaminergic Responsiveness in Detoxified Cocaine-Dependent Subjects," Nature, Vol. 386, No. 6627, 1997, pp. 830-833. http://dx.doi.org/10.1038/386830a0

[17] N. D. Volkow, G. J. Wang, L. Maynard, J. S. Fowler, B. Jayne, et al., "Effects of Alcohol Detoxification on Dopamine D2 Receptors in Alcoholics: A Preliminary Study," Psychiatry Research: Neuroimaging, Vol. 116, No. 3, 2002, pp. 163-172. http://dx.doi.org/10.1016/S0925-4927(02)00087-2

[18] N. D. Volkow, G. J. Wang, H. Begleiter, B. Porjesz, J. S. Fowler, et al., "High Levels of Dopamine D2 Receptors in Unaffected Members of Alcoholic Families: Possible Protective Factors," Archives of General Psychiatry, Vol. 63, No. 9, 2006, pp. 999-1008.

http://dx.doi.org/10.1001/archpsyc.63.9.999

[19] E. Tupala, H. Hall, K. Bergström, T. Mantere, P. Räsänen, et al., "Dopamine D2 Receptors and Transporters in Type 1 and 2 Alcoholics Measured with Human Whole Hemisphere Autoradiography," Human Brain Mapping, Vol. 20, No. 2, 2003, pp. 91-102. http://dx.doi.org/10.1002/hbm.10129

[20] E. Tupala, H. Hall, K. Bergström, T. Mantere, P. Räsänen, et al., "Different Effect of Age on Dopamine Transporters in the Dorsal and Ventral Striatum of Controls and Alcoholics," Synapse, Vol. 48, No. 4, 2003, pp. 205-211. http://dx.doi.org/10.1002/syn.10206

[21] R. M. Weinshilboum, D. M. Otterness, C. L. Szumlanski, "Methylation Pharmacogenetics: Catechol O-Methyltransferase, Thiopurine Methyltransferase, and Histamine NMethyltransferase," Annual Review of Pharmacology and Toxicology, Vol. 39, 1999, pp. 19-52. http://dx.doi.org/10.1146/annurev.pharmtox.39.1.19

[22] J. Chen, B. K. Lipska, N. Halim, Q. D. Ma, M. Matsumoto, et al., "Functional Analysis of Genetic Variation in Catechol-O-Methyltransferase (COMT): Effects on mRNA, Protein, and Enzyme Activity in Postmortem Human Brain," American Journal of Human Genetics, Vol. 75, No. 5, 2004, pp. 807-821. http://dx.doi.org/10.1086/425589

[23] X. Caldu, P. Vandrell, D. Bartres-Faz, I. Clemente, N. Bargallo, et al., "Impact of the COMT Val 108/158 Met and DAT Genotypes on Prefrontal Function in Healthy Subjects," NeuroImage, Vol. 37, No. 4, 2007, pp. 14371444. http://dx.doi.org/10.1016/j.neuroimage.2007.06.021
[24] A. Diamond, "Consequences of Variation in Genes That Affect Dopamine in Prefrontal Cortex," Cerebral Cortex, Vol. 17, No.1, 2007, pp. i161-i170. http://dx.doi.org/10.1093/cercor/bhm082

[25] M. J. Kreek, D. A. Nielsen, K. S. LaForge, "Genes Associated with Addiction: Alcoholism, Opiate, and Cocaine Addiction," Neuromolecular Medicine, Vol. 5, No. 1, 2004, pp. 85-108. http://dx.doi.org/10.1385/NMM:5:1:085

[26] D. J. Vandenbergh, L. A. Rodriguez, I. T. Miller, G. R. Uhl and H. M. Lachman, "High-Activity Catechol-OMethyltransferase Allele Is More Prevalent in Polysubstance Abusers," American Journal of Medical Genetics, Vol. 74, No. 4, 1997, pp. 439-442. http://dx.doi.org/10.1002/(SICI)1096-8628(19970725)74: 4<439::AID-AJMG16>3.0.CO;2-J

[27] R. Horowitz, M. Kotler, E. Shufman, S. Aharoni, I. Kremer, et al., "Confirmation of an Excess of the High Enzyme Activity COMT val Allele in Heroin Addicts in a Family-Based Haplotype Relative Risk Study," American Journal of Medical Genetics, Vol. 96, No. 5, 2000, pp. 599-603.

http://dx.doi.org/10.1002/1096-8628(20001009)96:5<599 $\because$ AID-AJMG4>3.0.CO;2-O

[28] M. J. Kreek, G. Bart, C. Lilly, K. S. LaForge and D. A. Niel- sen, "Pharmacogenetics and Human Molecular Genetics of Opiate and Cocaine Addictions and Their Treatments," Pharmacological Reviews, Vol. 57, No. 1, 2005 , pp. 1-26. http://dx.doi.org/10.1124/pr.57.1.1

[29] M. J. Kreek, D. A. Nielsen, E. R. Butelman and K. S. LaForge, "Genetic Influences on Impulsivity, Risk Taking, Stress Responsivity and Vulnerability to Drug Abuse and Addiction," Nature Neuroscience, Vol. 8, No. 11, 2005, pp. 1450-1457. http://dx.doi.org/10.1038/nn1583

[30] S. Y. Hill, E. K. Hoffman, N. Zezza, A. Thalamuthu, D. E. Weeks, et al., "Dopaminergic Mutations: Within-Family Association and Linkage in Multiplex Alcohol Dependence Families" American Journal of Medical Genetics Part B Neuropsychiatry Genetics, Vol. 147, No. 4, 2008. pp. 517-526. http://dx.doi.org/10.1002/ajmg.b.30630

[31] M. D. Lezak, D. B. Howieson, E. D. Bigler and D. Tranel, "Neuropsychological Assessment," 5th Edition, Oxford University Press, New York, 2012.

[32] S. A. Brown, S. F. Tapert, E. Granholm and D. C. Delis, "Neurocognitive Functioning of Adolescents: Effects of Protracted Alcohol Use," Alcohol: Clinical and Experimental Research, Vol. 24, No. 2, 2000, pp. 164-171. http://dx.doi.org/10.1111/j.1530-0277.2000.tb04586.x

[33] P. R. Giancola and H. B. Moss, "Executive Cognitive Functioning in Alcohol Use Disorders," In: M. Galanter Ed., Recent Developments in Alcoholism, Vol. 14: The Consequences of Alcoholism, Plenum Press, New York, 1998, pp. 227-251. http://dx.doi.org/10.1007/0-306-47148-5_10

[34] S. F. Tapert and S. A. Brown, "Substance Dependence, Family History of Alcohol Dependence and Neuropsychological Functioning in Adolescence," Addiction, Vol. 95, No. 7, 2000, pp. 1043-1053. http://dx.doi.org/10.1046/j.1360-0443.2000.95710436.x

[35] J. T. Nigg, E. Poon, H. E. Fitzgerald, J. M. Glass, M. M. Wong, et al., "Neuropsychological Executive Functioning 
in Children at Elevated Risk for Alcoholism: Findings in Early Adolescence," Journal of Abnormal Psychology, Vol. 113, No. 2, 2004, pp. 302-314. http://dx.doi.org/10.1037/0021-843X.113.2.302

[36] K. D. Tessner and S. Y. Hill, "Neural Circuitry Associated with Risk for Alcohol Use Disorders," Neuropsychology Review, Vol. 20, No. 1, 2010, pp. 1-20. http://dx.doi.org/10.1007/s11065-009-9111-4

[37] H. A. Wishart, R. M. Roth, A. J. Saykin, C. H. Rhodes, G. J. Tsongalis, et al., "COMT Val ${ }^{158}$ Met Genotype and Individual Difference in Executive Function in Healthy Adults," Journal of the International Neuropsychological Society, Vol. 17, No. 1, 2011, pp. 174-180. http://dx.doi.org/10.1017/S1355617710001402

[38] H. Xu, C. B. Kellendonk, E. H. Simpson, J. G. Keilp, G. E. Bruder, et al., "DRD2 C957T Polymorphism Interacts with the COMT Val ${ }^{158}$ Met Polymorphism in Human Working Memory," Schizophrenia Research, Vol. 90, No. 1-3, 2007, pp. 104-107. http://dx.doi.org/10.1016/j.schres.2006.10.001

[39] M. F. Gosso, E. J. C. deGeus, T. J. C. Polderman, D. I. Boomsma, P. Heutink and D. Posthuma, "Catechol OMethyl Transferase and Dopamine D2 Receptor Gene Polymorphisms: Evidence of Positive Heterosis and Gene-Gene Interaction on Working Memory Functioning," European Journal of Human Genetics, Vol. 16, No. 9, 2008, pp. 1075-1082. http://dx.doi.org/10.1038/ejhg.2008.57

[40] C. Stelzel, U. Basten, C. Montag, M. Reuter and C. J. Fiebach, "Effects of Dopamine-Related Gene-Gene Interactions on Working Memory Component Processes," The European Journal of Neuroscience, Vol. 29, No. 5, 2009 pp. 1056-1063. http://dx.doi.org/10.1111/j.1460-9568.2009.06647.x

[41] J. Zinkstok, N. Schmitz, T. van Amelsvoort, M. de Win, W. van den Brink, et al., "The COMT Val ${ }^{158}$ Met Polymorphism and Brain Morphometry in Healthy Young Adults," Neuroscience Letters, Vol. 405, No. 1-2, 2006, pp. 34-39. http://dx.doi.org/10.1016/j.neulet.2006.06.034

[42] W. D. Taylor, S. Züchner, M. E. Payne, D. F. Messer, T. J. Doty, et al., "The COMT Val ${ }^{158}$ Met Polymorphism and Temporal Lobe Morphometry in Healthy Adults," Psychiatry Research Neuroimaging, Vol. 155, No. 2, 2007, pp. 173-177.

http://dx.doi.org/10.1016/j.pscychresns.2007.01.005

[43] D. Bartres-Faz, C. Junque, J. M. Serra-Grabulosa, A. Lopez-Alomar, A. Moya, et al., "Dopamine DRD2 Taq1 Polymorphism Associates with Caudate Nucleus Volume and Cognitive Performance in Memory Impaired Subjects," Neuroreport, Vol. 13, No. 9, 2002, pp. 1121-1125. http://dx.doi.org/10.1097/00001756-200207020-00010

[44] G. T. Voelbel, M. E. Bates, J. F. Buckman, G. Pandina and R. L. Hendren, "Caudate Nucleus Volume and Cognitive Performance: Are They Related to Childhood Psychopathology? Biological Psychiatry, Vol. 60, No. 9, 2006, pp. 942-950. http://dx.doi.org/10.1016/j.biopsych.2006.03.071

[45] W. J. Chambers, J. Puig-Antich, M. Hirsch, P. Paez, P. Ambrosini, et al., "The Assessment of Affective Disorders in Children and Adolescents by Semi-Structured Interview," Archives of General Psychiatry, Vol. 42, No. 7,
1985, pp. 696-702.

http://dx.doi.org/10.1001/archpsyc. 1985.0179030006400 $\underline{8}$

[46] S. Y. Hill, J. Locke, L. Lowers and J. Connolly, "Psychopathology and Achievement in Children at High Risk for Developing Alcoholism," Journal of the American Academy of Child \& Adolescent Psychiatry, Vol. 38, No. 7, 1999, pp. 883-891.

http://dx.doi.org/10.1097/00004583-199907000-00019

[47] L. N. Robins, J. Wing, H. U. Wittchen, J. E. Helzer, T. F. Babor, et al., "The Composite International Diagnostic Interview. An Epidemiological Instrument Suitable for use in Conjunction with Different Diagnostic Systems and in Different Cultures," Archives of General Psychiatry, Vol. 45, No. 12, 1988, pp. 1069-1077. http://dx.doi.org/10.1001/archpsyc.1988.0180036001700 $\underline{3}$

[48] L. B. Cottler, L. E. Robins and J. E. Helzer, "The Reliability of the CIDI-SAM: A Comprehensive Substance Abuse Interview," British Journal of Addiction, Vol. 84, No. 7, 1989, pp. 801-814.

http://dx.doi.org/10.1111/j.1360-0443.1989.tb03060.x

[49] V. A. Magnotta, G. Harris, N. C. Andreason, D. S. O'Leary, W. T. C. Yuh and D. Heckel, "Structural MR Image Processing Using BRAINS2 Toolbox," Compute- rized Medical Imaging and Graphics, Vol. 26, No. 4, 2002, pp. 251-264.

http://dx.doi.org/10.1016/S0895-6111(02)00011-3

[50] W. S. Tae, S. S. Kim, K. U. Lee, E. C. Nam and K. W. Kim, "Validation of Hippocampal Volumes Measures Using a Manual Method and Two Automated Methods (FreeSurfer and IBASPM) in Chronic Major Depressive Disorder," Neuroradiology, Vol. 50, No. 7, 2008, pp. 569-581. http://dx.doi.org/10.1007/s00234-008-0383-9

[51] J. C. Looi, O. Lindberg, B. Liberg, V. Tatham, R. Kumar, et al., "Volumetrics of the Caudate Nucleus: Reliability and Validity of a New Manual Tracing Protocol," Psychiatry Research, Vol. 163, No. 3, 2008, pp. 279-288. http://dx.doi.org/10.1016/j.pscychresns.2007.07.005

[52] R. M. Reitan and D. Wolfson, "The Halstead-Reitan Neuropsychological Test Battery: Theory and Clinical Interpretation," Neuropsychology Press, Tucson, 1985.

[53] R. M. Reitan and D. Wolfson, "Neuropsychological Evaluation of Young Children. Manual for the Administration and Scoring of the Reitan-Indiana Neuropsychological Test Battery," Neuropsychology Press, Tucson, 1990.

[54] R. M. Reitan, "Trail Making Test Results for Normal and Brain-Damaged Children," Perceptual and Motor Skills, Vol. 33, No. 2, 1971, pp. 575-581. http://dx.doi.org/10.2466/pms.1971.33.2.575

[55] T. N. Tombaugh, "Trail Making Test A and B: Normative Data Stratified by Age and Education," Archives of Clinical Neuropsychology, Vol. 19 No. 2, 2004, pp. 203214. http://dx.doi.org/10.1016/S0887-6177(03)00039-8

[56] I. Sánchez-Cubillo, J. A. Periáñez, D. Adrover-Roig, J. M. Rodríguez-Sánchez, M. Ríos-Lago, et al., "Construct Validity of the Trail Making Test: Role of Task-Switching, Working Memory, Inhibition/Interference Control, and Visuomotor Abilities," Journal of the International Neuro- 
psychological Society, Vol. 15 No. 3, 2009, pp. 438-450. http://dx.doi.org/10.1017/S1355617709090626

[57] C. J. Golden, "Stroop Color and Word Test: A Manual for Clinical and Experimental Uses," Stoelting Co., Chicago, 1978.

[58] The Psychological Corporation, "WAIS-III/WMS-III Updated Technical Manual," San Antonio, 2002.

[59] L. K. Jacobsen, K. R. Pugh, W. E. Menel and J. Gelernter, "C957T Polymorphism of the Dopamine D2 Receptor Gene Modulates the Effect of Nicotine on Working Memory Performance and Cortical Processing Efficiency," Psychopharmacology, Vol. 188, No. 4, 2006, pp. 530-540. http://dx.doi.org/10.1007/s00213-006-0469-1

[60] E. V. Sullivan, A. Deshmukh, E. De Rosa, M. J. Rosenbloom and A. Pfefferbaum, "Striatal and Forebrain Nuclei Volumes: Contribution to Motor Function and Working Memory Deficits in Alcoholism," Biological Psychiatry, Vol. 57, No. 7, 2005, pp. 768-776. http://dx.doi.org/10.1016/j.biopsych.2004.12.012

[61] F. X. Castellanos, J. N. Giedd, P. Eckburg, W. L. Marsh, A. C. Vaituzis, et al., "Quantitative Morphology of the Caudate Nucleus in Attention Deficit Hyperactivity Disorder," American Journal of Psychiatry, Vol. 151, No. 12, 1994, pp. 1791-1796.

[62] F. X. Castellanos, P. P. Lee, W. Sharp, N. O. Jeffries, D. K. Greenstein, et al., "Developmental Trajectories of Brain Volume Abnormalities in Children and Adolescents with Attention-Deficit/Hyperactivity Disorder," The Jour- nal of the American Medical Association, Vol. 288, No. 14, 2001, pp. 1740-1748.

http://dx.doi.org/10.1001/jama.288.14.1740

[63] A. Cubillo, R. Halari, A. Smith, E. Taylor and K. Rubia, "A Review of Fronto-Striatal and Fronto-Cortical Brain Abnormalities in Children and Adults with Attention De- ficit Hyperactivity Disorder (ADHD) and New Evi- dence for Dysfunction in Adults with ADHD During Mo- tivation and Attention," Cortex, Vol. 48, No. 2, 2012, pp. 194215. http://dx.doi.org/10.1016/j.cortex.2011.04.007

[64] J. H. Barnett, P. B. Jones, T. W. Robbins and U. Miller, "Effects of the Catechol-O-Methyltransferase Val ${ }^{158} \mathrm{Met}$ Polymorphism on Executive Function: A Meta-Analysis of the Wisconsin Card Sort Test in Schizophrenia and Healthy Controls," Molecular Psychiatry, Vol. 12, No. 5, 2007, pp. 502-509. http://dx.doi.org/10.1038/sj.mp.4001973

[65] M. M. Hirvonen, L. Ville, J. Hirvonen, U. Personen, K. Nagren, et al., "C957T Polymorphism of the Human Dopamine D2 Receptor Gene Predicts Extrastriatal Dopamine Receptor Availability in Vivo," Progress in NeuroPsychopharmacology \& Biological Psychiatry, Vol. 33, No. 4, 2009, pp. 630-636. http://dx.doi.org/10.1016/j.pnpbp.2009.02.021

[66] C. D. Swagell, B. R. Lawford, I. P. Hughes, J. Voisey, G. F. Feeney, et al., "DRD2 C957T and Taq1A Genotyping Reveals Gender Effects and Unique Low-Risk and High-Risk Genotypes in Alcohol Dependence," Alcohol and Alcoholism, Vol. 47, No. 4, 2012, pp. 397-403. http://dx.doi.org/10.1093/alcalc/ags047

[67] H. A. Flynn, S. Marcus, K. L. Barry and F. C. Blow, "Rates and Correlates of Alcohol Use among Pregnant Women in Obstetrics Clinics," Alcohol: Clinical and Experimental Research, Vol. 27, No. 1, 2003, pp. 81-87. http://dx.doi.org/10.1111/j.1530-0277.2003.tb02725.x

[68] A. B. Hollingshead, "Four Factor Index of Social Status," Yale University, New Haven, 1975.

[69] L. M. Dunn and L. M. Dunn, "Peabody Picture Vocabulary Test," 3rd Edition, American Guidance Service, Circle Pines, 1997. 